\title{
Solution-Derived Sodalite Made with Si- and Ge-Ethoxide Precursors for Immobilizing Electrorefiner Salt \\ Brian J. Riley, ${ }^{*}$ William C. Lepry, Jarrod V. Crum \\ Pacific Northwest National Laboratory, Richland, WA 99352
}

\begin{abstract}
Chlorosodalite has the general form of $\mathrm{Na}_{8}\left(\mathrm{AlSiO}_{4}\right)_{6} \mathrm{Cl}_{2}$ and this paper describes experiments conducted to synthesize sodalite with a solution-based approach to immobilize a simulated spent electrorefiner salt solution containing a mixture of alkali, alkaline earth, and lanthanide chlorides. The reactants used were the salt solution, $\mathrm{NaAlO}_{2}$, and either $\mathrm{Si}\left(\mathrm{OC}_{2} \mathrm{H}_{5}\right)_{4}$ or $\mathrm{Ge}\left(\mathrm{OC}_{2} \mathrm{H}_{5}\right)_{4}$. Additionally, seven different glass binders at loadings of 5 mass $\%$ were evaluated as sintering aids for consolidating the as-made powders using a cold-press-and-sinter technique. This process of using alkoxide additives for the Group IV component can be used to produce large quantities of sodalite at near-room temperature as compared to a method where colloidal silica was used as the silica source. However, the small particle sizes inhibited densification during heat treatment.
\end{abstract}

Keywords: sodalite, electrochemical waste forms, eutectic salt, ethoxide, alkoxide

\section{Introduction}

The future of nuclear power production in the U.S. is uncertain, but, in order to maximize

\footnotetext{
*Corresponding author: brian.riley@pnnl.gov; (509)372-4651 (phone), (509)372-5997 (fax)
} 
the efficiency of the nuclear fuel cycle, the fuel will likely have to be recycled through a series of reprocessing steps. Several potential recycle methods have been proposed and one of them requires that the fuel be dissolved in a $\mathrm{LiCl}-\mathrm{KCl}$ eutectic salt within an electrorefiner. Once this salt is saturated with fission products released from the fuel, these components must be removed or the salt must be replaced to maintain separations efficiency.

The current baseline approach for immobilizing the spent salt is chlorosodalite, which has the general formula of $\mathrm{Na}_{8}\left(\mathrm{AlSiO}_{4}\right)_{6} \mathrm{Cl}_{2}$. The baseline sodalite developed by Argonne National Laboratory and Idaho National Laboratory is the most commonly studied waste form in the US for encapsulating the entire spent salt $[1,2]$. The typical method for making this waste form is to occlude the salt in zeolite $4 \mathrm{~A}$ at elevated temperatures $\left(\sim 500{ }^{\circ} \mathrm{C}\right)$, mix in $\sim 25$ mass $\%$ of a glass sintering aid, and then fire the mixture at $\sim 900-950{ }^{\circ} \mathrm{C}$.

An alternative way to making the sodalite is with a solution-based approach [3-5]. One solution-based method $[3,4]$ used colloidal silica, $\mathrm{NaAlO}_{2}$, and a salt solution to make sodalite at near-room temperature $\left(65^{\circ} \mathrm{C}\right)$, and those samples were referred to as S5A pellets. This process had some limitations where the sodalite production was limited at the elevated firing temperatures required to get high density pellets and the high processing temperatures usually led to chloride volatility and, subsequently, nepheline formation. However, even small amounts (1-7 mass\%) of a borosilicate glass sintering aid (NBS-1 [6]) improved these results and these samples are referred to as S6 pellets [3].

The current work presents a modified approach to the S5A/S6 technique with organic forms of Group IV additives, i.e., $\mathrm{Si}\left(\mathrm{OC}_{2} \mathrm{H}_{5}\right)_{4}$ (also called tetraethyl orthosilicate or TEOS) and $\mathrm{Ge}\left(\mathrm{OC}_{2} \mathrm{H}_{5}\right)_{4}$, which are also referred to as silicon ethoxide and germanium ethoxide, respectively. The $\mathrm{Ge}\left(\mathrm{OC}_{2} \mathrm{H}_{5}\right)_{4}$ precursor was selected as a potential option to reduce the 
consolidation temperature of the product considering that $\mathrm{GeO}_{2}$ melts at a much lower temperature $\left(1116{ }^{\circ} \mathrm{C}[7]\right)$ than $\mathrm{SiO}_{2}\left(1710^{\circ} \mathrm{C}[8]\right)$. Both of these compounds hydrolyze in the presence of water and undergo polycondensation reactions. This process can be controlled by adjusting the ratio of water to the organic precursors (on a molar basis), and this was studied previously in acid- and base-catalyzed reactions [9-12] and an example of how this process works for $\mathrm{Si}\left(\mathrm{OC}_{2} \mathrm{H}_{5}\right)_{4}$ is shown in Equation (1).

$$
\begin{gathered}
2 \mathrm{Si}\left(\mathrm{OC}_{2} \mathrm{H}_{5}\right)_{4}+2 \mathrm{H}_{2} \mathrm{O} \rightarrow 2 \mathrm{Si}\left(\mathrm{OC}_{2} \mathrm{H}_{5}\right)_{3} \mathrm{OH}+2 \mathrm{C}_{2} \mathrm{H}_{5} \mathrm{OH} \rightarrow \\
\left(\mathrm{OC}_{2} \mathrm{H}_{5}\right)_{3} \mathrm{Si}-\mathrm{O}-\mathrm{Si}\left(\mathrm{OC}_{2} \mathrm{H}_{5}\right)_{3}+\mathrm{H}_{2} \mathrm{O}+2 \mathrm{C}_{2} \mathrm{H}_{5} \mathrm{OH}
\end{gathered}
$$

While solution-derived minerals, including sodalite [39-44], are often found in the literature, it is not as common to see solution-based processes using alkoxides precursors. Latturner et al. [45] performed hydrothermal synthesis of sodalite using aluminum isopropoxide, TEOS, $\mathrm{NaOH}$, and $\mathrm{AgNO}_{3}$ or $\mathrm{TlNO}_{3}$ but this account is rare in the literature. The work presented here shows a simplified low-temperature route for making sodalite precursors using $\mathrm{Si}\left(\mathrm{OC}_{2} \mathrm{H}_{5}\right)_{4}$ or $\mathrm{Ge}\left(\mathrm{OC}_{2} \mathrm{H}_{5}\right)_{4}$, a mixed chloride salt waste, and $\mathrm{NaAlO}_{2}$ that can be combined with a glass powder and then fired to produce a glass-bonded sodalite monolith. The primary reason for investigating the organic precursors was to see if their reactivities would be different from colloidal silica, leading to a difference in the sodalite yield or a more preferred morphology in the as-made product. Also, seven different glass sintering aids were evaluated for improving sodalite yield and minimizing porosity in the fired pellets.

\section{Methods}

\subsection{Solution-based process}

The basic process for making all of the samples was similar with a few exceptions for each batch. In all cases, the goal was to achieve sodalite, nominally $\mathrm{Na}_{8}\left(\mathrm{AlSiO}_{4}\right)_{6} \mathrm{Cl}_{2}$. However, 
the stoichiometry used in these experiments was not batched as nominal and additional $\mathrm{NaAlO}_{2}$ was added to make up for the lack of $\mathrm{Na}$ in the salt and help drive the exchange of $\mathrm{Na}$ in the sodalite for $\mathrm{Li}$ and $\mathrm{K}$ into the glass phase. Also, the ratio of $\mathrm{Cl}$ to cations in the salt was not 1:1 because of the $\mathrm{LnCl}_{3}$ and $\mathrm{BaCl}_{2}$ (see Table 1) so this additional $\mathrm{Na}$ was also present to supplement the alkali content to balance the $\mathrm{Cl}$. The residual $\mathrm{Al}_{2} \mathrm{O}_{3}$ from the excess $\mathrm{NaAlO}_{2}$ was expected to incorporate into the glass phase.

For the $\mathrm{Si}\left(\mathrm{OC}_{2} \mathrm{H}_{5}\right)_{4}$-based samples (called $\mathrm{S} 5 \mathrm{C}$ ), $30.0 \mathrm{~mL}$ of salt solution (see Table 1) was added to a $250 \mathrm{~mL}$ beaker with a serpentine platinum stirring wire and this was heated to $75{ }^{\circ} \mathrm{C}$ while stirring. Then, $52.8 \mathrm{~mL}$ of $\mathrm{Si}\left(\mathrm{OC}_{2} \mathrm{H}_{5}\right)_{4}(99.0 \%$ purity, Sigma-Aldrich, St. Louis, MO) was added to the beaker while stirring. This was followed by the addition of $51.0 \mathrm{~mL}$ of $\mathrm{NaAlO}_{2}$ (38\% solution, USALCO, LLC, Baltimore, MD) and $13.8 \mathrm{~mL}$ of absolute ethanol. For the S5C pellets, $2.05 \mathrm{~g}$ of glass sintering aid (5 mass\%) was added into the solution and stirred. After the glass was added, the viscosity sharply increased through the process of an exothermic reaction $(\sim 30 \mathrm{~s})$. Each beaker was placed in a drying oven overnight at $105^{\circ} \mathrm{C}$ and the resulting products were powdered for homogenization.

For the $\mathrm{Ge}\left(\mathrm{OC}_{2} \mathrm{H}_{5}\right)_{4}$-based sample (called S5D), a 1/4-scale batch was made. Here, $7.5 \mathrm{~mL}$ of salt solution was added to a $100 \mathrm{~mL}$ beaker. Then, $13.2 \mathrm{~mL}$ of $\mathrm{Ge}\left(\mathrm{OC}_{2} \mathrm{H}_{5}\right)_{4}(97 \%$ solution, Alfa Aesar, Ward Hill, MA) was added to the beaker while stirring as was done previously. Then, $12.75 \mathrm{~mL}$ of $\mathrm{NaAlO}_{2}$ was added followed by $3.45 \mathrm{~mL}$ of absolute ethanol. The beaker was placed in a drying oven overnight at $105{ }^{\circ} \mathrm{C}$ and the resulting product was powdered for homogenization.

\subsection{Glass binder preparation}

The compositions of all glass sintering aids are presented in Table 2 as well as the 
predicted properties (if known) of viscosity $(\eta)$-temperature relationships, melting temperature $\left(T_{\mathrm{M}}\right)$, and bulk density $\left(\rho_{\mathrm{b}}\right)$. Each glass was added as a powder during the solution-based process discussed in the previous section. The volume of each glass powder was measured using a $\mathrm{He}$ pycnometer (Micromeritics AccuPyc II 1340, Norcross, GA) through a series of 5 purges and 10 measurements that were averaged. Mass values were measured with an analytical balance (PR2003 DeltaRange, Mettler-Toledo, Inc., Columbus, OH; $\pm 0.003 \mathrm{~g}$ precision) and then the pycnometer calculated the average $\rho_{\mathrm{b}}$. The average standard deviation of all 7 binders evaluated was $\pm 0.003 \times 10^{3} \mathrm{~kg} \mathrm{~m}^{-3}$.

The sodium borosilicate glass sintering aids, denoted as SA-\#\#, were formulated based on their lower $T_{\mathrm{M}}$ 's compared to NBS-1 and were labeled based on the temperatures (i.e., 700, 750, 800, and $850^{\circ} \mathrm{C}$ ) at which $\eta \sim 100 \mathrm{~Pa} \cdot \mathrm{s}$ based on predictions with SciGlass models (v 7.0, ITC, Inc., Newton, MA). A melt-quench technique was used to make $250 \mathrm{~g}$ of each of the SA\#\#\# glass binders, which were batched from $\mathrm{SiO}_{2}, \mathrm{Na}_{2} \mathrm{CO}_{3}$, and $\mathrm{H}_{3} \mathrm{BO}_{3}$. The as-batched powders were mixed in an agate mill, melted in a lidded $\mathrm{Pt} / 10 \% \mathrm{Rh}$ crucible at various $T_{\mathrm{M}}$ 's (see Table 2) for $1 \mathrm{hr}$, and quenched on an Inconel plate. This glass was ground in a tungsten carbide mill, remelted, requenched, and then ground to the final powder.

The NBS-1 glass developed by Vienna et al. [6] was also used in previous work with the S6 pellets [3]. The NaAlP glass was selected based on past success as a sintering aid (NaAlP-B4) for an apatite mineral waste form [13]. The NBS-1 and NaAlP binders were provided by collaborators as powders and not made new for this study. The TePbO glass was selected because it has a high loading for the same mixed salt waste that was used in this study [14-17]. The $\mathrm{TePbO}$ glass was made by mixing $\mathrm{TeO}_{2}$ and $\mathrm{PbO}$ with a composition of $78 \% \mathrm{TeO}_{2} / 22 \% \mathrm{PbO}$ (by mass) in a mortar and pestle and melting in a covered $\mathrm{Pt} / 10 \% \mathrm{Rh}$ crucible for $20 \mathrm{~min}$ at 
$700{ }^{\circ} \mathrm{C}$. The melt was quenched on an Inconel plate and powdered.

\subsection{Pellet Preparation and Firing}

Following drying and homogenization, $\sim 2.5 \mathrm{~g}$ of the as-dried powders were weighed and uniaxially pressed into pellets at $2.5 \times 10^{7} \mathrm{~Pa}\left(3.6 \times 10^{3}\right.$ pounds per square inch) in a stainless steel die. The unfired "green" densities were calculated by measuring volume with a set of calipers and applying the aforementioned mass. Then, the pellets were placed on a dense alumina sintering plate and loaded into a Lindberg furnace (Thermal Product Solutions, Rochester, NY). Specimens were heated at $1{ }^{\circ} \mathrm{C} \mathrm{min}^{-1}$ up to the maximum firing temperature between 550-

$950{ }^{\circ} \mathrm{C}$, held for $8 \mathrm{~h}$, and then furnace-cooled at $\sim 10{ }^{\circ} \mathrm{C} \min ^{-1}$. Following firing, pellets were broken into quadrants and characterized.

\subsection{Density and Porosity}

The $\rho_{\mathrm{b}}$ was measured by taking accurate mass and geometric volume measurements (average height and diameter) of the pellets before firing (green density) and after firing (sintered density). Pellet masses were measured with the PR2003 DeltaRange analytical balance and volumetric measurements were taken using digital calipers with a precision of $\pm 0.01 \mathrm{~mm}$. Archimedes' method was also performed to measure $\rho_{\mathrm{b}}$ using ethanol (EtOH).

Here, the specimen masses were measured dry $\left(m_{\mathrm{dry}}\right)$ on the PR2003 DeltaRange analytical balance and then submerged in absolute $\mathrm{EtOH}$ within a vacuum desiccator where the air was removed from the open porosity and these voids were back-fill with absolute EtOH. After $\geq 20$ min of sitting in the ethanol under vacuum (1.3-6.7 Pa), the submerged mass $\left(m_{\text {sub }}\right)$ was measured using an Archimedes apparatus. Then, the pellet was removed from the EtOH and the excess EtOH on the surface of the pellet was removed by blotting it on an EtOH-soaked 
cloth, and then the pellet saturated with $\mathrm{EtOH}$ was weighed ( $\left.m_{\text {sat }}\right)$. The temperature of the EtOH was monitored and used to calculate the $\rho_{\mathrm{b}}$ of the pellet according to Equation (2) where the $\rho_{\text {EtOH }}$ was the density of ethanol $\left(\rho\right.$ EtOH $\left.=-8.54 \times 10^{-4 *} T+0.806 ; T=15-25^{\circ} \mathrm{C}[18]\right)$.

$$
\rho_{\mathrm{b}}=\left(m_{\mathrm{dry}} * \rho_{\mathrm{EtOH}}\right) /\left(m_{\mathrm{sat}}-m_{\mathrm{sub}}\right)
$$

From these data, the open porosity $(\phi)$ of the specimens was measured based both on mass differences $\left(\phi_{\mathrm{m}}\right)$ and the ratio of $\rho_{\mathrm{b}}$ to the theoretical density $\left(\rho_{\mathrm{t}}\right)$ of sodalite $\left(\sim 2.27 \times 10^{3} \mathrm{~kg} \mathrm{~m}^{-3}\right)\left(\phi_{\rho}\right)$ as seen in Equation (3) [19]. The $\rho_{\mathrm{t}}$ values were calculated using Equation (4) where $\rho_{\mathrm{i}}$ and $m_{\mathrm{i}}$ were the calculated density and mass fraction of the $i$-th crystalline phase, respectively, determined using X-ray diffraction (XRD). This approach does not account for the amorphous fraction so it is considered an estimation of the true $\rho_{\mathrm{b}}$.

$$
\begin{gathered}
\phi_{\mathrm{m}}=\left(m_{\mathrm{sat}}-m_{\mathrm{dry}}\right) /\left(m_{\mathrm{sat}}-m_{\mathrm{sub}}\right) \\
\phi_{\rho}=1-\left(\rho_{\mathrm{b}} / \rho_{\mathrm{t}}\right) \\
\rho_{\mathrm{t}}=\sum_{i=1}^{n} \rho_{i} m_{i}
\end{gathered}
$$

\section{$2.5 X$ X-Ray Diffraction}

Specimens of as-made and fired materials were powdered in a tungsten carbide milling chamber and then analyzed with XRD. A Bruker ${ }^{\circledR}$ D8 Advance (Bruker AXS Inc., Madison, WI) equipped with a $\mathrm{Cu} \mathrm{K} \alpha$ target set to a power level of $40 \mathrm{kV}$ and $40 \mathrm{~mA}$ was used to collect diffraction patterns. The detector used was a LynxEye ${ }^{\mathrm{TM}}$ position-sensitive detector with a scan range of $3^{\circ} 2 \theta$. Typical scan parameters used for specimen analysis were $5-70^{\circ} 2 \theta$ with a step of $0.015^{\circ} 2 \theta$ and a 0.3 -s dwell at each step. Bruker AXS ${ }^{\odot}$ EVA (v14) and Topas (v4.2) software were used to identify and quantify phase assemblages. A standard was not added to the samples prior to analysis so the amorphous (or nanocrystalline) portion in each sample was not included 
in the phase distribution analysis.

\subsection{Scanning Electron Microscopy and Energy Dispersive Spectroscopy}

Both fractured and cross-sectioned specimens were observed with scanning electron microscopy (SEM) and energy dispersive spectroscopy (EDS). A JSM-7001F with a field emission gun (JEOL USA, Inc. Peabody, MA) was equipped with an EDAX Apollo II $30 \mathrm{~mm}^{2}$ Si drift detector (AMETEK, Berwyn, PA) for compositional analysis. Specimens were coated with palladium prior to analysis. Both secondary electron and backscattered electron detectors were used for imaging.

\section{Results and Discussion}

\subsection{Phase Distribution and Morphology}

As shown in Table 3 [20-26], the as-made S5C (Si-based) samples had high sodalite fractions at $\sim 82-98 \%$ (of the crystalline content). In contrast to previous work where colloidal silica was used instead of TEOS [16], the use of TEOS may be the preferred silica precursor for maximizing sodalite yield in the as-made product without having to prolong the mixing duration.

Figure 1 provides a comparison of the phase distribution in S5C pellets made with different sintering aids and fired at different temperatures. All of the SA sintering aids behaved quite similarly with a maximum sodalite concentration at the lower sintering temperatures (550$600{ }^{\circ} \mathrm{C}$ ) and an inverse correlation between the mass\% of sodalite and Na-Al-Si-O phases (e.g., nepheline, carnegieite) with increasing firing temperatures. This inverse relationship was similarly observed with S5C-TePbO and S5C-NBS1 but was more pronounced in the data for S5C-NaAlP. This was attributed to Cl-volatility with increased firing temperatures.

Figure 2 shows the XRD spectra for the as-made S5D (Ge-based) sample as well as the 
product after a heat-treatment at $750{ }^{\circ} \mathrm{C}$ for $8 \mathrm{~h}$. The primary phase $(\sim 81.4$ mass $\%)$ in the asmade sample was $\mathrm{Na}_{8}\left(\mathrm{AlGeO}_{4}\right)_{6} \mathrm{Cl}_{2}$ (Ge-sodalite, ICSD\#65664 [27], where ICSD is the Inorganic Crystal Structure Database). The minor components included unreacted $\mathrm{NaCl}$ (7.0 mass\%, ICSD\#61662 [28]), KCl (6.5 mass\%, ICSD\#28938 [29]), and LiCl (1.9 mass\%, ICSD\#26909 [30]) as well as $\mathrm{KH}_{3} \mathrm{Ge}_{7} \mathrm{O}_{16} \cdot 3 \mathrm{H}_{2} \mathrm{O}$ (3.2 mass\%, ICSD\#34094 [31]).

For the heat-treated S5D sample, not all of the phases could be quantified because of unfit peaks but the primary phase was $\mathrm{Na}_{8}\left(\mathrm{AlGeO}_{4}\right)_{6} \mathrm{Cl}_{2}$. An $h k l$ phase based off of $\mathrm{Na}_{1.74} \mathrm{Mg}_{0.79} \mathrm{Al}_{0.15} \mathrm{Si}_{1.06} \mathrm{O}_{4}$ [32] with the orthorhombic Pbca space group $(a=10.5, b=10.4, c=$ $5.25 \AA$ ) was created during Reitveld refinement to fit several of the unfit peaks as per a peak location and intensity fit with the diffraction pattern using EVA phase identification (International Centre for Diffraction Data database 1999). Several minor components were found in the fired pellet including unreacted salts (i.e., $\mathrm{NaCl}$ [28] and $\mathrm{KCl}$ [29]), $\mathrm{KAlSi}_{3} \mathrm{O}_{8}$ (ICSD\#73416 [33]), and $\mathrm{GeO}_{2}$ (ICSD\#158589 [34]) as well as several structural (not chemical) matches for phases like lithium silicates (i.e., $\mathrm{Li}_{2} \mathrm{SiO}_{3} \quad \mathrm{ICSD}_{100402}$ [35] and $\mathrm{Li}_{2} \mathrm{Si}_{2} \mathrm{O}_{5}$ ICSD\#15414 [36]). This shows that the Ge-sodalite can be synthesized with this salt composition and the $\mathrm{Ge}\left(\mathrm{OC}_{2} \mathrm{H}_{5}\right)_{4}$ precursor. Although the substitution of $\mathrm{Si}$ for $\mathrm{Ge}$, in theory, should reduce the required consolidation temperatures, the $\phi$ in the fired pellet was $\sim 40 \%$. Thus, with the added disadvantage of the $\mathrm{Ge}\left(\mathrm{OC}_{2} \mathrm{H}_{5}\right)_{4}$ precursor being notably more expensive than $\mathrm{Si}\left(\mathrm{OC}_{2} \mathrm{H}_{5}\right)_{4}$, this process was abandoned but might warrant further investigation with a new glass binder optimized for this particular formulation if lower processing temperatures were a limitation for a given waste due to selective volatility of salt constituents.

Figure 3 provides some microstructure comparisons between solution-based materials made with colloidal silica from a previous study $[3,14]$ and some from the current study with 
TEOS as the silica source. It is apparent by comparing the scales of the microstructure that the TEOS-based product has a smaller grain size by an order of magnitude ( 10 -fold difference). Also, a clear distinction can be found between the sodalite and nepheline fractions based on the Cl EDS map. The presence of free lanthanides is denoted by the La map where this fraction appears to be present at the grain boundary between the nepheline and sodalite phases. This suggests that a larger fraction of glass binder might be required to fully incorporate the lanthanide fission products into the glass phase.

\subsection{Pellet Densities and Porosity}

The full data set for density and porosity measurements on the alternative sintering aids is presented in Table 4. The $\rho_{\mathrm{t}}$ for sodalite varies slightly depending on the true composition of the sodalite $\left(2.27 \times 10^{3} \mathrm{~kg} \mathrm{~m}^{-3}\right.$ [37] ICSD\#98812 to $2.30 \times 10^{3} \mathrm{~kg} \mathrm{~m}^{-3}$ [38] ICSD\#166827). It should be noted that Equation (4), which is used for calculating $\rho_{\mathrm{t}}$, contains a source of error in that it does not account for the density and mass fraction of the amorphous fraction. The glass sintering aids have higher $\rho_{\mathrm{b}}$ values (see Table 2$)$ than sodalite $\left(\sim 2.29 \times 10^{3} \mathrm{~kg} \mathrm{~m}^{-3}\right)$, which will inflate the true $\rho_{\mathrm{t}}$ values, although this will only be a minor contribution due to the low mass of glass added (5 mass $\%)$. Also, some of the data for " $\%$ of $\rho_{\mathrm{t}}$ " are probably artificially inflated and the data for $\phi_{\rho}$ values in Table 4 must be considered in comparisons. The maximum density observed was at $92 \%$ of $\rho_{\mathrm{t}}\left(\mathrm{S} 5 \mathrm{C}-\mathrm{SA} 700\right.$ at $\left.750^{\circ} \mathrm{C}\right)$.

The optimum heat-treatment temperature to achieve maximum density for specimens with the sintering aids was $\sim 750-850{ }^{\circ} \mathrm{C}$ for all except NBS-1, which was $\sim 950{ }^{\circ} \mathrm{C}$ (possibly higher). Adding NaAlP or TePbO sintering aids did not increase pellet densities where maximum achieved $\%$ of $\rho_{\mathrm{t}}$ values were $55 \%$ (at $750{ }^{\circ} \mathrm{C}$ ) and $56 \%$ (at $850{ }^{\circ} \mathrm{C}$ ), respectively. Thus, these sintering aid compositions were not as reactive with the as-made materials as the SA\#\#\# and 
NBS-1 glasses.

Figure 4a provides a summary of the pellet densities at different firing temperatures for the S5C pellets and Figure $4 \mathrm{~b}$ provides a comparison of both sodalite mass \% (of crystalline fraction) and the $\%$ of $\rho_{\mathrm{t}}$ values for all samples fired at $750{ }^{\circ} \mathrm{C}$. Here, we see that the maximum density with the NBS-1 glass sintering aid was not confirmed over the temperatures tested. This is attributed to the fact that the glass has the highest $\mathrm{SiO}_{2}$ content (60 mass\%) as well as a higher $\eta$ and $T_{\mathrm{M}}$ than all of the other sintering aids evaluated here. From Figure 4, it can be seen that the SA-\#\#\# sintering aids were effective at closing the pores and allowing for moderate sodalite fraction to form during firing at lower temperatures than are normally used for producing the baseline ceramic waste form $\left(\sim 915^{\circ} \mathrm{C}\right)$. It should also be noted that the NaAlP and $\mathrm{TePbO}$ samples showed the highest sodalite fractions following the $750{ }^{\circ} \mathrm{C}$ firing at 81.8 and 79.7 mass $\%$, respectively.

Figure 5 provides a comparison of the " $\%$ of $\rho_{\mathrm{t}}$ " and "mass $\%$ of sodalite in the crystalline fraction" for each sintering aid at different firing temperatures. Figure 5 also includes data from a previous study [3] where sodalite samples were made using colloidal silica instead of $\mathrm{Si}\left(\mathrm{OC}_{2} \mathrm{H}_{5}\right)_{4}$. Here, the most promising candidates are towards the upper right corner of the plot where both target properties are maximized. From this plot, it is evident that the SA\#\#\# sintering aids performed well to close the porosity while still allowing sodalite to form during firing although all of the data seem to settle along a boundary shown by the dotted arc revealing the limitations of the current work.

The effect of increased viscosity for NBS-1 over the SA\#\#\# sintering aids was evident by the high $\phi$ for these samples at temperatures $\leq 750{ }^{\circ} \mathrm{C}$. When comparing all of the data obtained with the NBS1 sintering aid, i.e., S6 made with colloidal silica and S5C-NBS1 made with 
$\mathrm{Si}\left(\mathrm{OC}_{2} \mathrm{H}_{5}\right)_{4}$, it is apparent that the colloidal silica formulations had comparable values of $\%$ of $\rho_{\mathrm{t}}$ but noticeably higher sodalite fractions. This could be a result of the size of the starting as-made sodalite material but is also likely related to the sodalite fraction in the as-made starting material.

\section{Conclusions}

The work presented here demonstrates the syntheses of sodalite using either $\operatorname{Si}\left(\mathrm{OC}_{2} \mathrm{H}_{5}\right)_{4}$ or $\mathrm{Ge}\left(\mathrm{OC}_{2} \mathrm{H}_{5}\right)_{4}$ along with $\mathrm{NaAlO}_{2}$ and a simulated electrorefiner salt solution containing a mixture of alkali, alkaline earth, and lanthanide chlorides at near-room temperature. The as-made products showed high sodalite yields of $\sim 82-98$ mass $\%$ for the Si-based materials and $\sim 81$ mass \% for the Ge-based sample. The seven glass binders that were evaluated performed quite differently from one another. The four SA\#\#\# binders all performed similarly with maximum densification achieved at temperatures of $750-8500^{\circ} \mathrm{C}$ whereas the NBS-1 glass densified at much higher temperatures $\left(\geq 950^{\circ} \mathrm{C}\right)$ and the NaAlP and $\mathrm{TePbO}$ glasses did not show evidence of densification at any of the temperatures evaluated. These binders were not optimized and so further improvements could be made to densify at reduced temperatures with modifications to the glass compositions. The primary limitation to densification time and temperature is the volatility of $\mathrm{Cl}$, which results in sodalite decomposition to nepheline.

\section{Acknowledgements}

Pacific Northwest National Laboratory is operated by the U.S. Department of Energy under Contract Number DE-AC05-76RL01830. The authors thank Jared Kroll for his help with measuring density on the NaAlP glass binder, Nathan Canfield for helpful comments, and Josef Matyáš for helpful discussions. This work was conducted with funding support from the Department of Energy Office of Nuclear Energy under the Fuel Cycle Research and Development Program with partial support from a subcontract from Idaho National Laboratory 
through the Korean Atomic Energy Research Institute.

\section{References}

[1] K.J. Bateman, C.J. Knight, C.W. Solbrig. 2007. Current Status of Ceramic Waste Form Development. INL/INT-06-11736, Rev. 1. Idaho National Laboratory, Idaho Falls, ID.

[2] W.L. Ebert. 2005. Testing to Evaluate the Suitability of Waste Forms Developed for Electrometallurgically-Treated Spend Sodium-Bonded Nuclear Fuel for Disposal in the Yucca Mountain Repository. ANL-05/43. Argonne National Laboratory-East, Argonne, IL.

[3] B.J. Riley, J.V. Crum, J. Matyáš, J.S. McCloy, W.C. Lepry, J. Am. Ceram. Soc. 95 (10) (2012) 3115-3123.

[4] B.J. Riley, D.A. Pierce, S.M. Frank, J. Matyáš, C.A. Burns, J. Nucl. Mater. 459 (2015) 313322.

[5] E.R. Vance, J. Davis, K. Olufson, I. Chironi, I. Karatchevtseva, I. Farnan, J. Nucl. Mater. 420 (1-3) (2012) 396-404.

[6] J.D. Vienna, J. Luey, P.R. Hrma, D.E. Smith, R.D. Scheele, H.L. Wigent, J.V. Crum. 1998. Proc. of the Environmental Issues and Waste Management Technologies in the Ceramic and Nuclear Industries IV, 93, pp. 399-407, Ed. J. C. Marra and G. T. Chandler. The American Ceramics Society, Westerville, $\mathrm{OH}$.

[7] A.W. Laubengayer, D.S. Morton, J. Am. Chem. Soc. 54 (1932) 2303-2320.

[8] J.N. Wilson, Sand. Clay Miner. 2 (3) (1935) 127-130.

[9] C.J. Brinker, K.D. Keefer, D.W. Schaefer, C.S. Ashley, J. Non-Cryst. Solids 48 (1982) $47-$ 64.

[10] C.J. Brinker, K.D. Keefer, D.W. Schaefer, R.A. Assink, B.D. Kay, C.S. Ashley, J. Non- 
Cryst. Solids 63 (1984) 45-59.

[11] I.M. Thomas, "Method for producing glass precursor compositions and glass compositions therefrom," patent number 3799754, 1974.

[12] C.J. Brinker, S.P. Mukherjee, J. Mater. Sci. 16 (1981) 1980-1988.

[13] I.W. Donald, B.L. Metcalfe, S.K. Fong, L.A. Gerrard, D.M. Strachan, R.D. Scheele, J. Nucl. Mater. 361 (1) (2007) 78-93.

[14] B.J. Riley, B.T. Rieck, J.V. Crum, J. Matyas, J. McCloy, S.K. Sundaram, J.D. Vienna. 2010. Alternative Electrochemical Salt Waste Forms, Summary of FY2010 Results. FCRDWAST-2010-000129. Pacific Northwest National Laboratory, Richland, WA.

[15] B.J. Riley, B.T. Rieck, J.S. McCloy, J.V. Crum, S.K. Sundaram, J.D. Vienna, J. Nucl. Mater. 424 (1-3) (2012) 29-37.

[16] B.J. Riley, J.S. McCloy, J.V. Crum, C.P. Rodriguez, C.F. Windisch Jr., W.C. Lepry, J. Matyas, M.P. Westman, B.T. Rieck, J.B. Lang, D.A. Pierce. 2011. Alternative Electrochemical Salt Waste Forms, Summary of FY/CY2011 Results. FCRD-SWF-2012000028. Pacific Northwest National Laboratory, Richland, WA.

[17] B.J. Riley, J.S. McCloy, J.V. Crum, W.C. Lepry, C.P. Rodriguez, C.F. Windisch Jr., J. Matyas, M.P. Westman, B.T. Rieck, J.B. Lang, M.J. Olszta, D.A. Pierce. 2012. Alternative Electrochemical Salt Waste Forms, Summary of FY11-FY12 Results. FCRDSWF-2013-000025. Pacific Northwest National Laboratory, Richland, WA.

[18] S.W. Stratton, Standard density and volumetric tables, $6^{\text {th }}$ ed. Washington: Government Printing Office (1924).

[19] D.J. Lacks, R.G. Gordon, Phys. Rev. B 48 (5) (1993) 2889-2908.

[20] B. Beagley, C.M.B. Henderson, D. Taylor, Mineral. Mag. 46 (1982) 459-464. 
[21] I. Hassan, H.D. Grundy, Acta Cryst. C 39 (1983) 3-5.

[22] S. Hansen, L. Fälth, Zeolites 2 (3) (1982) 162-166.

[23] J.J. Pluth, J.V. Smith, J. Am. Chem. Soc. 102 (14) (1980) 4704-4708.

[24] S. Cartlidge, E.B. Keller, W.M. Meier, Zeolites 4 (3) (1984) 226-230.

[25] H. Ott, Z. Krystallogr. 63 (1926) 222-230.

[26] P. Stegmueller, "Strukturelle Untersuchungen an Verbindungen $\mathrm{Yb}_{\mathrm{m}} \mathrm{Cl}_{2 \mathrm{~m}+1}(\mathrm{~m}=6,8)$ und Chloroaluminaten von $\mathrm{Sr}$ und Ba sowie $\mathrm{Yb}, \mathrm{Sm}$ und Eu," Ph.D. dissertation Thesis, Universität Karlsruhe, 1997.

[27] M.E. Fleet, Acta. Cryst C. 45 (1989) 843-847.

[28] J.E. Nickels, M.A. Fineman, W.E. Wallace, J. Phys. Chem. 53 (1949) 625-628.

[29] W.T. Barrett, W.E. Wallace, J. Am. Chem. Soc. 76 (1954) 366-369.

[30] A.F. Levin'sh, M.E. Straumanis, K. Karlsons, Z. Phys. Chem. B.-Chem. E. 40 (1938) 146150.

[31] G.I. Sturua, E.L. Belokoneva, M.A. Simonov, N.V. Belov, Dokl. Akad. Nauk. SSSR 242 (1978) 1078-1081.

[32] R. Withers, C. Lobo, J. Thompson, S. Schmid, R. Stranger, Acta Cryst. B 53 (1997) 203220.

[33] J.-M. Zhang, J.-D. Ko, R.M. Hazen, C.T. Prewitt, Am. Mineral. 78 (1993) 493-499.

[34] J. Haines, J.M. Leger, C. Chateau, A.S. Pereira, Phys. Chem. Miner. 27 (2000) 575-582.

[35] H. Völlenkle, Z. Kristallogr. 154 (1-2) (1981) 77-81.

[36] F. Liebau, Acta Cryst. 14 (1961) 389-395.

[37] I. Hassan, S.M. Antao, J.B. Parise, Am. Mineral. 89 (2004) 359-364.

[38] G.O. Siqueira, É.G. Gravina, J.A.L.C. Resende, N.G. Fernandes, Am. Mineral. 24 (2009) 
41-43.

[39] N.C. Nielsen, H. Bildsøe, H.J. Jakobsen, P. Norby, Zeolites 11 (6) (1991) 622-632.

[40] J.O. Dickson, J.B. Harsh, M. Flury, W.W. Lukens, E.M. Pierce, Environ. Sci. Technol. 48 (21) (2014) 12851-12857.

[41] S. Bachmann, J.C. Buhl, Micropor. Mesopor. Mater. 28 (1) (1999) 35-47.

[42] J.M. Newsam, J.D. Jorgensen, Zeolites 7 (6) (1987) 569-573.

[43] J.C. Buhl, J. Löns, J. Solid State Chem. 112 (2) (1994) 243-250.

[44] V.I. Srdanov, W.T.A. Harrison, T.E. Gier, G.D. Stucky, A. Popitsch, K. Gatterer, D. Markgraber, H.P. Fritzer, J. Phys. Chem. 98 (17) (1994) 4673-4676.

[45] S.E. Latturner, J. Sachleben, B.B. Iversen, J. Hanson, G.D. Stucky, 103 (34) (1999) 71357144. 


\section{TABLES}

Table 1. Composition of spent electrochemical salt simulant where the representative fission products include all components except $\mathrm{KCl}$, $\mathrm{LiCl}$, and $\mathrm{NaCl}$.

\begin{tabular}{|l|c|c|c|}
\hline Component & Mass Fraction & Concentration $\left.\mathbf{g ~ L}^{-1}\right)$ & $\mathbf{M}\left(\right.$ moles L $\left.^{-1}\right)$ \\
\hline $\mathrm{KCl}$ & 0.3799 & 68.43 & 0.9179 \\
\hline $\mathrm{LiCl}$ & 0.2985 & 53.77 & 1.2683 \\
\hline $\mathrm{NaCl}$ & 0.1171 & 21.09 & 0.3609 \\
\hline $\mathrm{NdCl}$ & 0.0537 & 9.66 & 0.0386 \\
\hline $\mathrm{CsCl}$ & 0.0395 & 7.12 & 0.0423 \\
\hline $\mathrm{CeCl}_{3}$ & 0.0352 & 6.34 & 0.0257 \\
\hline $\mathrm{LaCl}_{3}$ & 0.0229 & 4.13 & 0.0168 \\
\hline $\mathrm{BaCl}_{2}$ & 0.0202 & 3.63 & 0.0174 \\
\hline $\mathrm{PrCl}_{3}$ & 0.0169 & 3.05 & 0.0123 \\
\hline $\mathrm{SmCl}_{3}$ & 0.0160 & 2.88 & 0.0112 \\
\hline Sum: & $\mathbf{1 . 0 0 0 0}$ & $\mathbf{1 8 0 . 1 1}$ & $\mathbf{2 . 7 1 1 6}$ \\
\hline
\end{tabular}


Table 2. Compositions (in mass \%) of glass sintering aids. Properties are listed and include the temperature at which predicted $\eta \sim 100 \mathrm{~Pa} \cdot \mathrm{s}$, the melting temperature $\left(T_{M}\right)$, and the bulk density $\left(\rho_{b}\right)$ measured with a He pycnometer. Some of the data was not available for TePbO or NaAIP for comparison.

\begin{tabular}{|l|r|c|c|c|c|c|c|}
\hline Components & NBS-1 & SA-700 & SA-750 & SA-800 & SA-850 & NaAIP & TePbO \\
\hline $\mathrm{SiO}_{2}$ & 60.00 & 28.57 & 40.83 & 42.5 & 48.31 & - & - \\
\hline $\mathrm{Na}_{2} \mathrm{O}$ & 15.00 & 38.32 & 37.49 & 32.88 & 34.89 & 24.57 & - \\
\hline $\mathrm{B}_{2} \mathrm{O}_{3}$ & 10.00 & 33.11 & 21.68 & 24.62 & 16.80 & 1.38 & - \\
\hline $\mathrm{Li}_{2} \mathrm{O}$ & 5.00 & - & - & - & - & - & - \\
\hline $\mathrm{Al}_{2} \mathrm{O}_{3}$ & 5.00 & - & - & - & - & 19.20 & - \\
\hline $\mathrm{ZrO}_{2}$ & 5.00 & - & - & - & - & - & - \\
\hline $\mathrm{P}_{2} \mathrm{O}_{5}$ & - & - & - & - & - & 54.85 & - \\
\hline $\mathrm{TeO}_{2}$ & - & - & - & - & - & - & 78.00 \\
\hline $\mathrm{PbO}^{T} \mathrm{where}_{-100 \mathrm{~Pa} \cdot \mathrm{s}}$ & 963 & 700 & 751 & 805 & 850 & (b) & $<600^{(\mathrm{a})}$ \\
\hline$T_{\mathrm{M}},{ }^{\circ} \mathrm{C}$ & $1250^{(\mathrm{a})}$ & 850 & 900 & 950 & 1000 & $742^{(\mathrm{c})}$ & $650^{(\mathrm{a})}$ \\
\hline$\rho_{\mathrm{b}}, \times 10^{3} \mathrm{~kg} \mathrm{~m}^{-3}$ & 2.561 & 2.527 & 2.542 & 2.551 & 2.544 & 2.490 & 6.169 \\
\hline
\end{tabular}

(a) These values are estimated

(b)These values are unknown

${ }^{(\mathrm{c})}$ This is the measured liquidus temperature $\left(T_{\mathrm{L}}\right)$ 
Table 3. Phase distribution of as-made S5C sodalite samples as determined with XRD whole pattern fitting where $\rho_{\mathrm{b}}$ is the calculated bulk density of the crystalline phase.* Note that the amorphous fraction was not determined.

\begin{tabular}{|c|c|c|c|c|c|c|c|c|c|}
\hline Crystalline phase & ICSD $^{\dagger}$ [Ref.] & $\begin{array}{c}\rho_{\mathrm{b}} \\
\left(\times 10^{3} \mathrm{~kg} \mathrm{~m}^{-3}\right)\end{array}$ & NBS1 & SA700 & SA750 & SA800 & SA850 & TePbO & NaAIP \\
\hline $\mathrm{Na}_{8}\left(\mathrm{AlSiO}_{4}\right)_{6} \mathrm{Cl}_{2}$ & $41188[20]$ & 2.30 & $93.2 \%$ & $96.3 \%$ & $97.8 \%$ & $98.2 \%$ & $87.9 \%$ & - & $96.3 \%$ \\
\hline $\mathrm{Na}_{8}\left(\mathrm{AlSiO}_{4}\right)_{6}(\mathrm{OH})_{2} * 2 \mathrm{H}_{2} \mathrm{O}$ & $36050[21]$ & 2.29 & - & - & - & - & - & $82.2 \%$ & - \\
\hline $\mathrm{Na}_{3}\left(\mathrm{AlSiO}_{4}\right)_{3}\left(\mathrm{H}_{2} \mathrm{O}\right)_{1.8}$ & $201460[22]$ & 2.36 & $4.9 \%$ & & $0.6 \%$ & $0.0 \%$ & $2.4 \%$ & $3.8 \%$ & $1.6 \%$ \\
\hline $\mathrm{Na}_{0.96} \mathrm{AlSiO}_{4}$ & $34100[23]$ & 1.52 & - & - & - & - & - & $11.3 \%$ & - \\
\hline $\mathrm{K}_{9} \mathrm{Al}_{9.7} \mathrm{Si}_{26.3} \mathrm{O}_{72}$ & 201596 [24] & 1.86 & - & - & - & - & $7.5 \%$ & - & \\
\hline $\mathrm{KCl}$ & $18014[25]$ & 1.99 & $1.9 \%$ & $2.2 \%$ & $1.6 \%$ & $1.8 \%$ & $2.2 \%$ & $2.7 \%$ & $2.1 \%$ \\
\hline $\mathrm{Ba}\left(\mathrm{AlCl}_{4}\right)_{2}$ & $56735[26]$ & 2.35 & - & $1.5 \%$ & - & - & - & - & \\
\hline SUM & - & - & $100.0 \%$ & $100.0 \%$ & $100.0 \%$ & $100.0 \%$ & $100.0 \%$ & $100.0 \%$ & $100.0 \%$ \\
\hline
\end{tabular}

*Note that some of these phases might not be chemistry matches but are structure matches and thus these values might not be exact but estimates

${ }^{\dagger}$ ICSD is the Inorganic Crystal Structure Database reference number from FindIt (v2014-2). 
Table 4. Measured porosity $\left(\phi_{\rho}\right)$, calculated $\rho_{\mathrm{t}}$ based on phase distribution, and $\%$ of theoretical density ( $\%$ of $\rho t)$ for several specimens. The error associated with $\phi_{\rho}$ is associated with that of the analytical balance $(<1 \%)$. The error associated with $\rho$ t and \% of $\rho_{\mathrm{t}}$ are higher because the mass fraction was not determined and the density of the amorphous phase could not be determined. Additionally, the $\rho_{\text {i }}$ values used for each phase to calculate $\rho_{\text {i }}$ using Equation (4) were estimated based on data in the ICSD. *The heattreatment temperatures resulting in the maximum $\%$ of $\rho_{\mathrm{t}}$ are shown in bold type.

\begin{tabular}{|c|c|c|c|c|}
\hline Binder & Firing temperature $\left({ }^{\circ} \mathrm{C}\right)$ & $\phi_{\rho}$ & $\rho_{\mathrm{t}}$ & $\%$ of $\rho_{\mathrm{t}}$ \\
\hline \multirow[t]{6}{*}{ NBS-1 } & 550 & $56 \%$ & 2.32 & $46 \%$ \\
\hline & 600 & $55 \%$ & 2.32 & $47 \%$ \\
\hline & 650 & $51 \%$ & 2.32 & $52 \%$ \\
\hline & 700 & $39 \%$ & 2.33 & $65 \%$ \\
\hline & 800 & $26 \%$ & 2.38 & $76 \%$ \\
\hline & 950 & $15 \%$ & 2.43 & $87 \%$ \\
\hline \multirow[t]{5}{*}{ SA-700 } & 550 & $49 \%$ & 2.32 & $54 \%$ \\
\hline & 600 & $34 \%$ & 2.31 & $68 \%$ \\
\hline & 650 & $13 \%$ & 2.35 & $90 \%$ \\
\hline & 750 & $11 \%$ & 2.37 & $92 \%$ \\
\hline & 850 & $14 \%$ & 2.37 & $90 \%$ \\
\hline \multirow[t]{7}{*}{ SA-750 } & 550 & $51 \%$ & 2.31 & $50 \%$ \\
\hline & 600 & $45 \%$ & 2.32 & $57 \%$ \\
\hline & 650 & $35 \%$ & 2.34 & $67 \%$ \\
\hline & 700 & $28 \%$ & 2.34 & $74 \%$ \\
\hline & 750 & $18 \%$ & 2.38 & $85 \%$ \\
\hline & 800 & $20 \%$ & 2.36 & $84 \%$ \\
\hline & 850 & $16 \%$ & 2.37 & $87 \%$ \\
\hline \multirow[t]{7}{*}{ SA-800 } & 550 & $56 \%$ & 2.32 & $46 \%$ \\
\hline & 600 & $48 \%$ & 2.32 & $55 \%$ \\
\hline & 650 & $27 \%$ & 2.33 & $75 \%$ \\
\hline & 700 & $15 \%$ & 2.35 & $87 \%$ \\
\hline & 750 & $12 \%$ & 2.36 & $91 \%$ \\
\hline & 800 & $15 \%$ & 2.36 & $89 \%$ \\
\hline & 850 & $18 \%$ & 2.39 & $85 \%$ \\
\hline \multirow[t]{6}{*}{ SA-850 } & 550 & $56 \%$ & 2.32 & $46 \%$ \\
\hline & 600 & $44 \%$ & 2.32 & $58 \%$ \\
\hline & 650 & $24 \%$ & 2.34 & $78 \%$ \\
\hline & 700 & $19 \%$ & 2.33 & $83 \%$ \\
\hline & 800 & $18 \%$ & 2.36 & $86 \%$ \\
\hline & 850 & $23 \%$ & 2.41 & $79 \%$ \\
\hline \multirow[t]{4}{*}{$\mathrm{TePbO}$} & 550 & $59 \%$ & 2.33 & $44 \%$ \\
\hline & 600 & $58 \%$ & 2.32 & $45 \%$ \\
\hline & 750 & $52 \%$ & 2.27 & $54 \%$ \\
\hline & 850 & $51 \%$ & 2.33 & $56 \%$ \\
\hline \multirow[t]{6}{*}{ NaAlP } & 550 & $55 \%$ & 2.29 & $46 \%$ \\
\hline & 600 & $55 \%$ & 2.30 & $47 \%$ \\
\hline & 650 & $58 \%$ & 2.29 & $44 \%$ \\
\hline & 750 & $48 \%$ & 2.30 & $55 \%$ \\
\hline & 850 & $50 \%$ & 2.48 & $50 \%$ \\
\hline & 950 & $54 \%$ & 2.54 & $50 \%$ \\
\hline
\end{tabular}




\section{FIGURES}

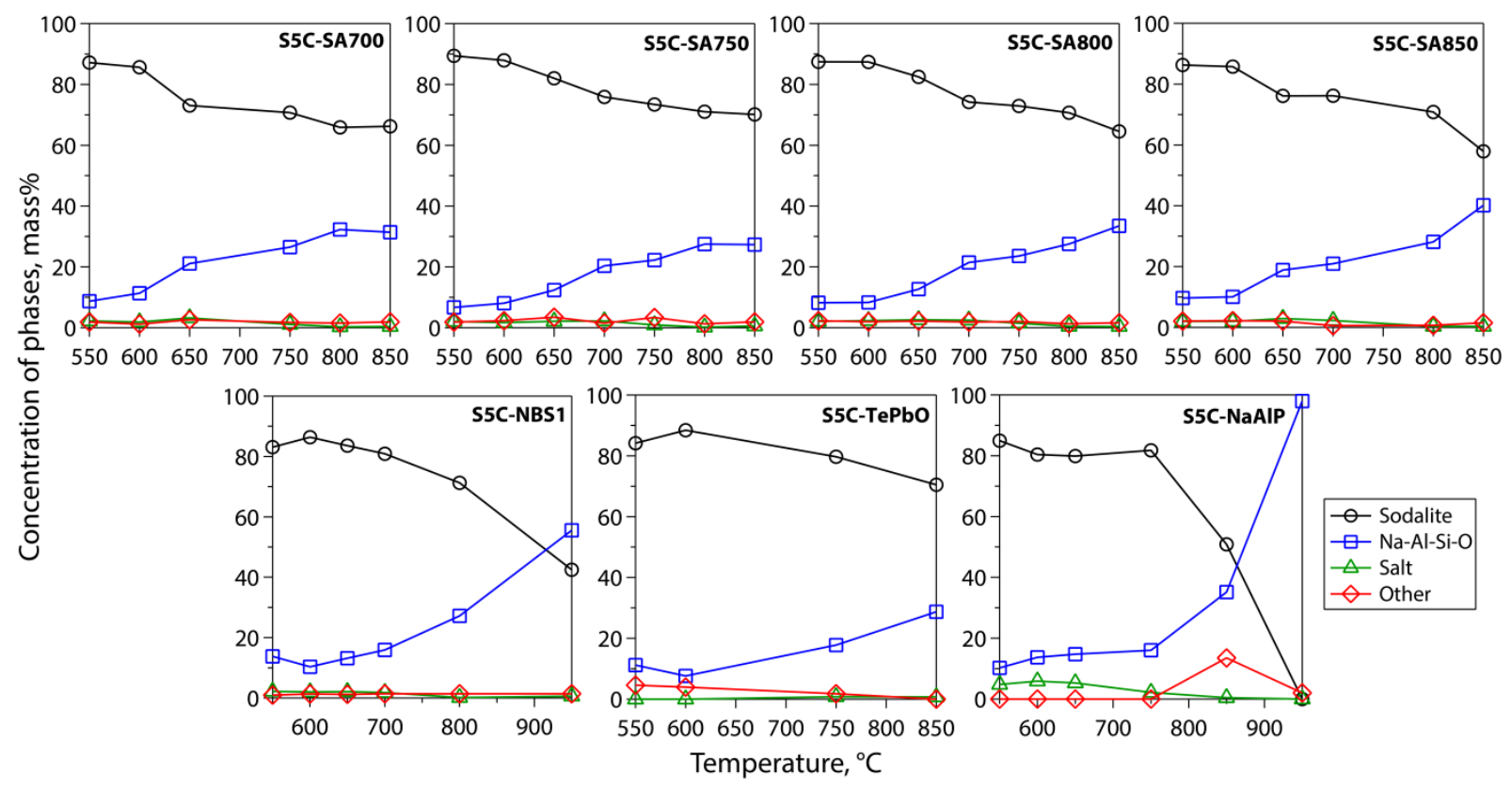

Figure 1. Phase distribution for the various S5C formulations with the different sintering aids fired at different temperatures. The legend presented in the lower right is valid for all. 


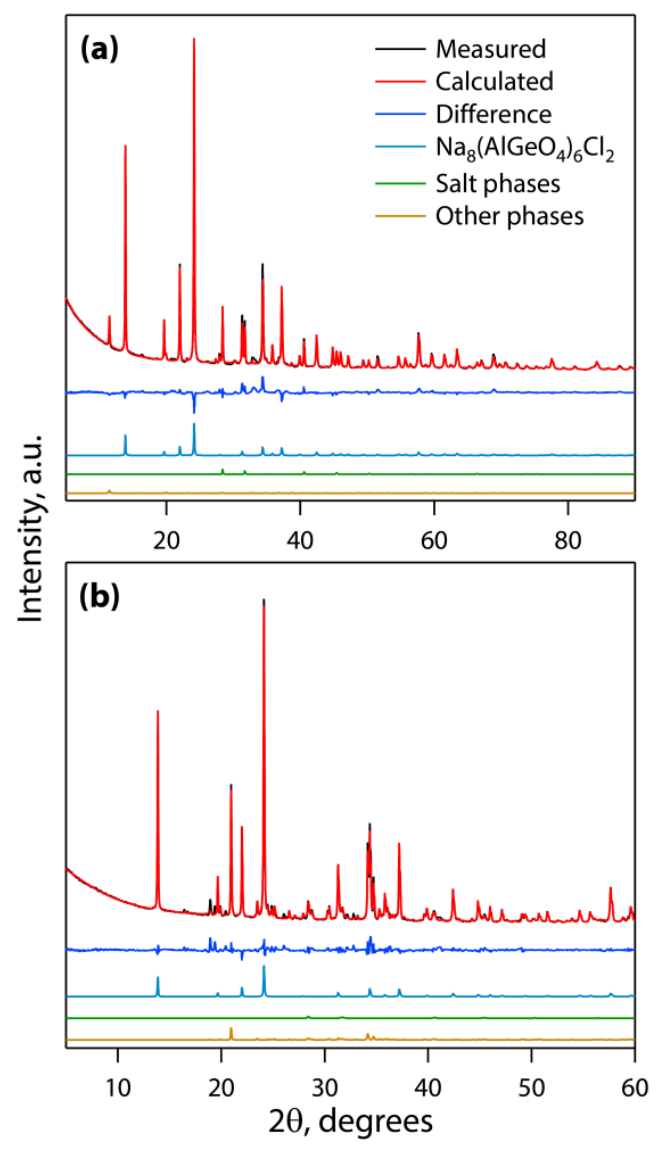

Figure 2. XRD on Ge-sodalite (S5D) samples both (a) as-made and (b) after firing at $750{ }^{\circ} \mathrm{C}$ for $8 \mathrm{hr}$. The "salt phases" include $\mathrm{NaCl}, \mathrm{KCl}$, and $\mathrm{LiCl}$ and the "Other phases" include a variety of different phases discussed in the text. 


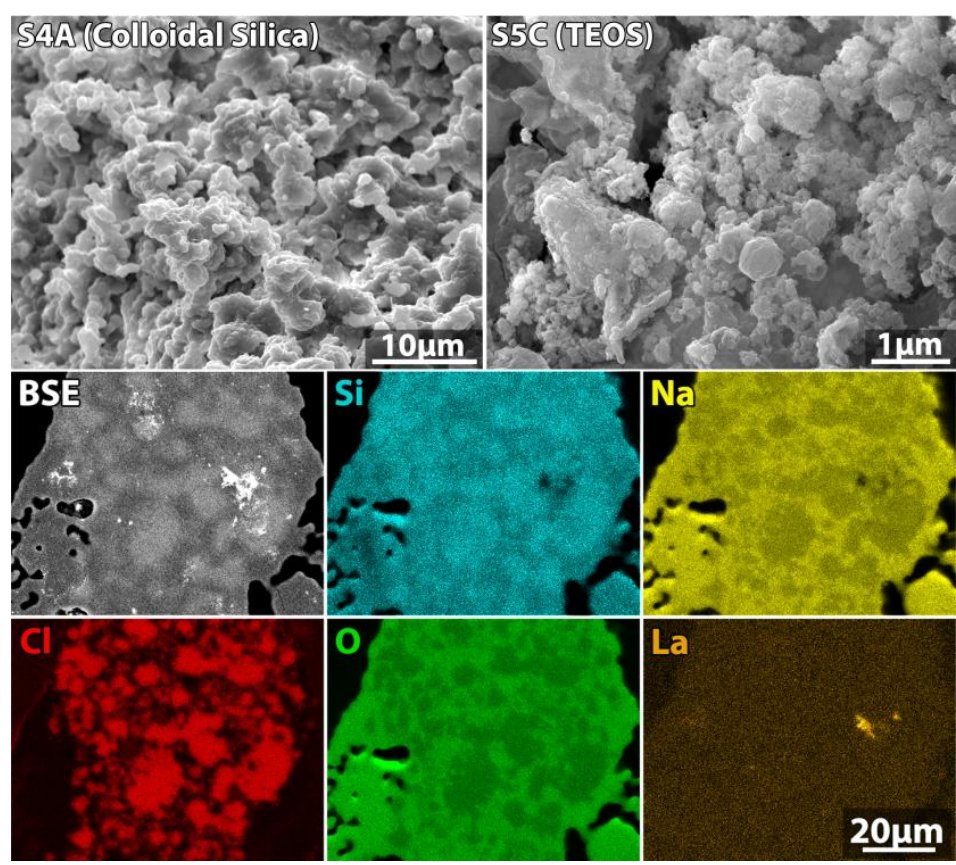

Figure 3. SEM micrographs of as-made sodalite samples S4 (from a previous study [3, 14]) and S5C (both without glass binders) as well as an EDS dot map on S5C showing elemental distribution and a clear distinction between the sodalite and nepheline phases by the chloride distribution. 

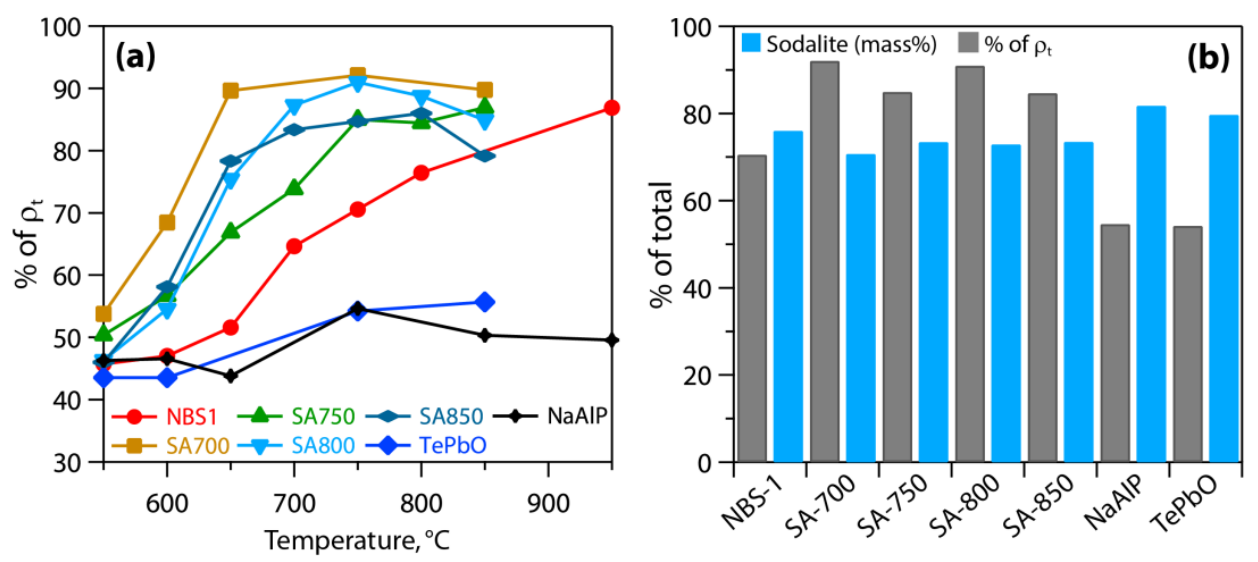

Figure 4. (a) Summary of pellet density as a function of firing temperature for $\mathrm{S5C}$ series specimens with 5 mass \% sintering aid. (b) Column chart comparing the mass \% of sodalite in each specimen with the $\%$ of $\rho_{\mathrm{t}}$ for all S5C specimens fired at $750{ }^{\circ} \mathrm{C}$ (note that in some cases, data at $750{ }^{\circ} \mathrm{C}$ was obtained by taking an average between data at 700 and $800{ }^{\circ} \mathrm{C}$ ). 


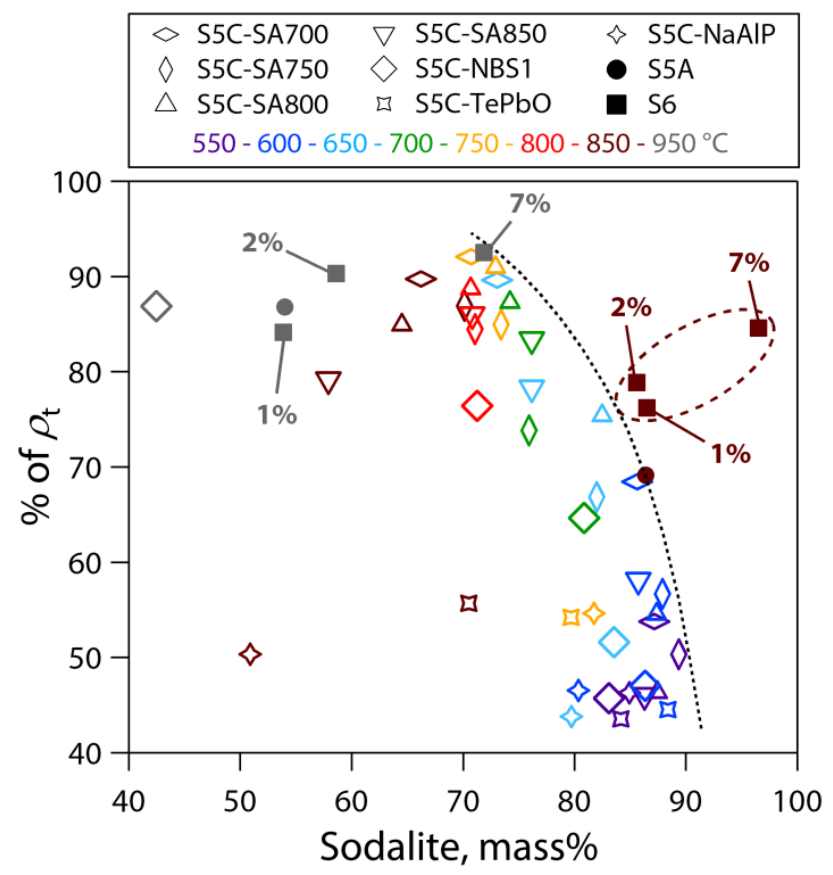

Figure 5. Comparison of sodalite and \% of $\rho_{t}$ for the S5A [3, 14], S6 [3, 14], and S5C specimens at different firing temperatures. The S5A specimens are shown with and without the NBS-1 sintering aid (1-7 mass\%) at different temperatures. Each sample is denoted with a different symbol and the firing temperature is denoted by the color as defined in the legend. The dotted blue line outlines the maximum density/sodalite attained for $\mathrm{Si}\left(\mathrm{OC}_{2} \mathrm{H}_{5}\right)_{4}$-based pellets in this study. 